\title{
FÉLIX HERNÁNDEZ Y LA RESTAURACIÓN DE LA MEZQUITA-CATEDRAL DE CÓRDOBA
}

\author{
Sebastián Herrero Romero
}

\begin{abstract}
La actividad profesional del arquitecto Félix Hernández (1889-1975) estuvo dedicada en buena parte a las investigaciones arqueológicas en los edificios más notables de la cultura islámica. Este artículo pretende mostrar las intervenciones que en materia de restauración llevó a cabo en la Mezquita-Catedral de Córdoba y los criterios que las guiaron. Apoyado siempre en el rigor de sus investigaciones arqueológicas y documentales, Hernández ha sido el arquitecto que durante un mayor periodo de tiempo ha participado en las labores de conservación de este edificio. Por ese motivo, nos interesa conocer la evolución de su actividad desde la etapa republicana hasta el franquismo y cuáles fueron las influencias en los criterios seguidos en su labor.

Palabras clave: Félix Hernández; Mezquita-Catedral; Córdoba; Arquitectura religiosa; Restauración patrimonial.
\end{abstract}

\section{FÉLIX HERNÁNDEZ AND THE RESTORATION OF THE MOSQUE-CATHEDRAL OF CORDOBA}

Felix Hernández's (1889-1975) professional activities as an architect were largely devoted to archaeological investigations in the most outstanding buildings of Islamic culture. This article deals with his restoration interventions in the Mosque-Cathedral of Cordoba and the criteria that guided them. Always based on the rigor of his archaeological and documentary research, Hernández was the architect involved for the longest period of time in the conservation work on this building. For this reason, it is interesting to examine the evolution of his activities from the Republican period through the Franco regime and discover the influences on the criteria used in his work.

Key words: Félix Hernández; Mosque-Cathedral; Cordoba; Religious architecture; Heritage restoration.

\section{Las investigaciones arqueológicas en la Mezquita}

Félix Hernández nació en Barcelona en 1889 y fue allí donde cursó los estudios de Arquitectura, titulándose en 1912. Pronto tuvo su primer contacto con la arqueología de campo al trabajar en 1915 en el levantamiento de uno de los sectores de Numancia, excavación dirigida por Manuel Aníbal Álvarez. La invitación de unos amigos para visitar Sevilla propició su deseo de establecerse en el sur, obteniendo primero plaza de arquitecto municipal en Linares y posteriormente en Córdoba. Aquí, paralelamente a su actividad profesional, contactó rápidamente con las perso- 
nalidades más destacadas de la escena cultural de la ciudad. En 1921 fue nombrado miembro de la Comisión Provincial de Monumentos y en 1924, tras la muerte de Ricardo Velázquez Bosco, quedó integrado en la Comisión Delegado-Directora de los trabajos de excavación del yacimiento de Madinat al-Zahra ${ }^{1}$.

Su labor profesional en la Mezquita-Catedral de Córdoba comenzó como auxiliar del arquitecto jefe de zona Pablo Gutiérrez Moreno durante unos pocos meses en 1930. A continuación trabajó a las órdenes de José $\mathrm{M}^{\mathrm{a}}$ Rodríguez Cano hasta mayo de 1936, momento en el que fue nombrado jefe de zona, cargo que desempeñó hasta su muerte en 1975. Félix Hernández actuó en el edificio situando la investigación y el conocimiento como prioridad, poniendo en relación las fuentes escritas con los datos de campo, propiciando un gran avance en el conocimiento. Antes incluso de su colaboración con Gutiérrez Moreno, Félix Hernández había comenzado a estudiar la Mezquita. En 1928 publicó su artículo "Arte musulmán. La techumbre de la Gran Mezquita de Córdoba" en Archivo Español de Arte y Arqueología ${ }^{2}$. En él estudió los tableros y las vigas que sirvieron a Velázquez Bosco para rehacer la techumbre en la ampliación de al-Hakam II. Velázquez Bosco debió estudiar con detenimiento estas piezas pero no dejó justificación escrita. Por tal motivo, Hernández se replanteó la procedencia y la posición de los fragmentos recuperados en la techumbre original, estableciendo diferentes hipótesis sobre su configuración y aclarando definitivamente la entrega de las vigas en los muros.

Félix Hernández comenzó en verano de 1930 las investigaciones arqueológicas en la Torre como ayudante de Pablo Gutiérrez Moreno, quien será jefe de zona durante un breve periodo de tiempo entre 1929 y 1930. Para dicha exploración se contaba con el decidido impulso de Manuel Gómez-Moreno, Director General de Bellas Artes en ese momento. Tras la renuncia de Gutiérrez Moreno, fue nombrado José $\mathrm{M}^{\mathrm{a}}$ Rodríguez Cano, sobrino Gómez-Moreno, quien continuó con Hernández como auxiliar. Conviene recordar que Rodríguez Cano se había titulado en 1929, por lo que la colaboración de Félix Hernández supuso sin lugar a dudas una gran ayuda para él. Hernández, que atesoraba 41 años, conocía en profundidad el edificio, estaba excavando en Madinat al-Zahra y empezaba a gozar de un gran prestigio por sus hallazgos y por la seriedad con la que realizaba su trabajo. En 1930 publicó Un aspecto de la influencia del arte califal en Cataluña y en 1932 San Miguel de Cuixá, iglesia del ciclo mozárabe catalán. Ambos artículos le permitirán darse a conocer en su Cataluña natal, toda vez que el mundo cultural madrileño ya lo conocía gracias a las publicaciones sobre las excavaciones en Madinat al-Zahra. Entre 1933 y 1935 será pensionado por la Junta de Ampliación de Estudios para la investigación del Influjo del arte del califato de Córdoba en Francia ${ }^{3}$.

En esta etapa como auxiliar de Rodríguez Cano se dedicará a realizar investigaciones con el fin de determinar los numerosos interrogantes que existían en esos momentos sobre la evolución del edificio. Como recuerda Nieto Cumplido, una de las labores determinantes de Hernández fue la "recopilación de forma exhaustiva de las fuentes históricas conocidas hasta ese momento" 4. En primer lugar, Félix Hernández continuó con la exploración de la Torre, buscando el alminar islámico. A la vez que se desescombraban los rellenos que ocultaban su estructura, se procedía al estudio de los textos. La gran cantidad de datos que irá obteniendo será

\footnotetext{
${ }^{1}$ Formaban esta Comisión Joaquín M $M^{a}$ Navascués, Rafael Castejón, Rafael Jiménez, Ezequiel Ruiz y el propio Félix Hernández.

${ }^{2}$ En 1925 Manuel Gómez-Moreno y Elías Tormo promovieron la creación de esta revista.

${ }^{3}$ Tras una primera estancia en 1933, realizará su segundo viaje en julio de 1935. Desde Perpignan escribió a Gómez-Moreno contándole el itinerario que tenía previsto realizar. Carta de Félix Hernández a Manuel Gómez-Moreno, 17 de julio de 1935, Fundación Rodríguez Acosta, Archivo Gómez-Moreno, Granada (AGM), correspondencia 1935.

${ }^{4}$ Nieto Cumplido, 1998: 160.
}

Arch. esp. arte, LXXXVIII, 349, ENERO-MARZO 2015, 1-18 ISSN: 0004-0428, eISSN: 1988-8511, doi: 10.3989/aearte.2015.01 


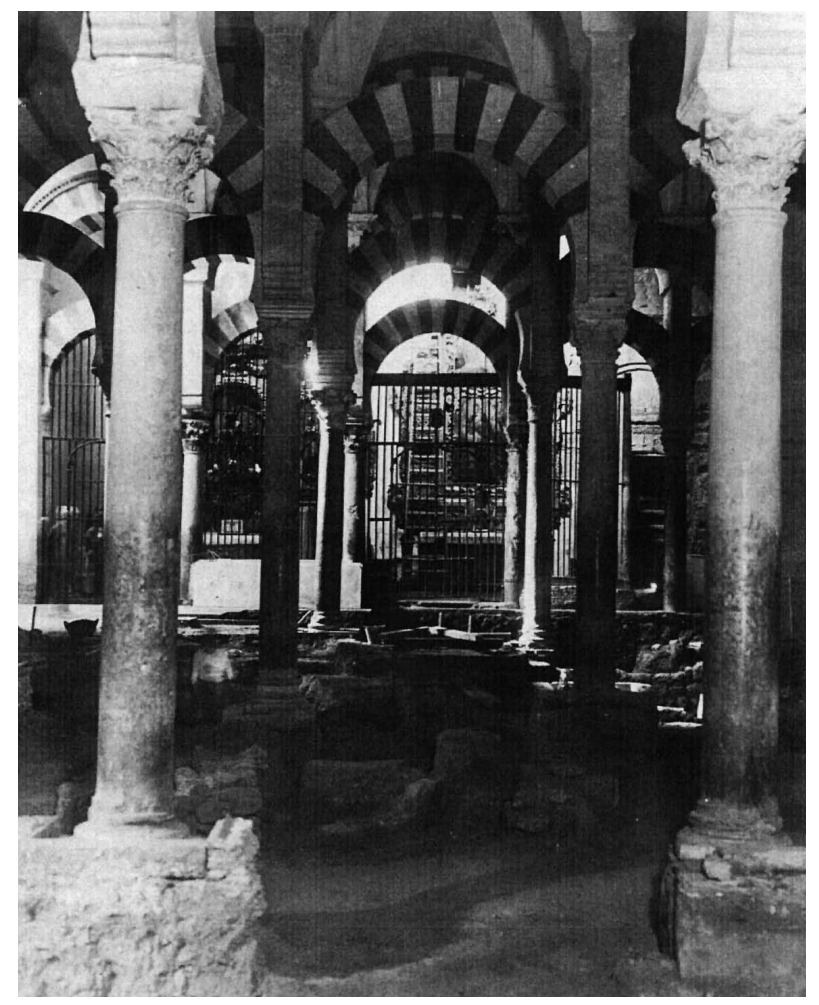

el germen de dos publicaciones: un texto sobre las dimensiones de orden general de la Mezquita publicado en 1961 bajo el título El codo en la historiografía árabe de la Mezquita Mayor de Córdoba y un estudio que vio la luz pocos días antes de su fallecimiento en 1975, titulado El alminar de Abd alRahman III en la Mezquita Mayor de Córdoba. Génesis y repercusiones.

Posteriormente, las intervenciones arqueológicas se centraron en el interior del edificio, trabajando fundamentalmente en los límites de la mezquita fundacional con las distintas ampliaciones. Hernández excavará en las 4 de las 5 naves occidentales de Abd al-Rahman I, tratando de encontrar los restos de la iglesia de San Vicente e intentando confirmar

Fig. 1. Excavación en las naves occidentales de la mezquita de Abd al-Rahman I, 1932. Museo Arqueológico de Córdoba, Archivo Félix Hernández, PO-47.

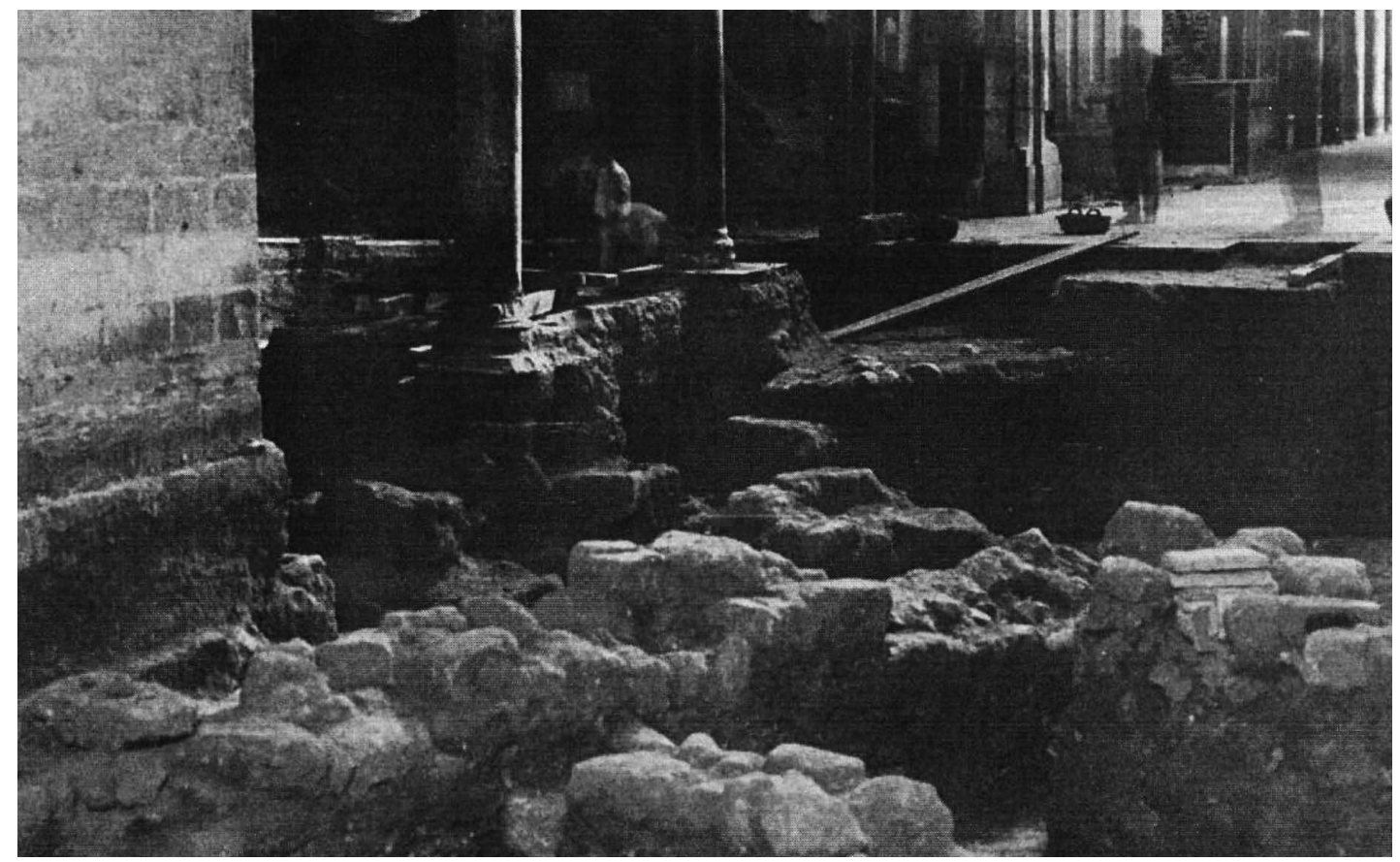

Fig. 2. Excavación en la nave central de la ampliación de Abd al-Rahman II, 1932. Museo Arqueológico de Córdoba, Archivo Félix Hernández, PO-47.

Arch. esp. arte, LXXXVIII, 349, ENERO-MARZO 2015, 1-18 ISSN: 0004-0428, eISSN: 1988-8511, doi: 10.3989/aearte.2015.01 
el número de naves de esa primera mezquita (figs. 1 y 2). Encontró restos de construcciones anteriores a Abd al-Rahman I, en concreto unos mosaicos que conformaban el pavimento de unas estancias y los restos murales de cerramiento elaborados con mampuesto y ladrillos, que Stylow dató en el siglo $\mathrm{VI}^{5}$ (fig. 3). Estas labores incluían también la exploración de las cimentaciones, aprovechando la excavación para recalzarlas con hormigón en masa (figs. 4 y 5). Paralelamente se estaba excavando tratando de identificar los límites de las sucesivas ampliaciones, localizando la cimentación del mihrab de Abd al-Rahman II bajo el pavimento de mármol colocado por Velázquez Bosco en la Capilla de Villaviciosa y una escalinata de acceso a una antigua puerta en el límite entre la nave oriental de Abd al-Rahman I y la ampliación de Almanzor.

En noviembre de 1932 Hernández planteó la necesidad de ir cerrando algunas partes de la excavación ya que su extensión comenzaba a ser un inconveniente, dejando prevista la colocación de la solería a su primitivo nivel. El joven Rodríguez Cano pidió opinión a Gómez-Moreno ${ }^{6}$, demostrando la ascendencia que éste tenía sobre ellos. A pesar de que no era ya Director General de Bellas Artes, los arquitectos encargados de la restauración del patrimonio reconocían la capacidad intelectual y el prestigio de Gómez-Moreno ${ }^{7}$. Esta obra supuso un rebaje de $34 \mathrm{~cm}$ y tuvo lugar en la nave central y las 5 naves occidentales de Abd al-Rahman I. La intención de esta recuperación de lo original tuvo como resultado dejar a la vista la mayoría de las basas, a la vez que se conseguía dar al interior del edificio una proporción más esbelta. Como muestra de la preocupación existente por la extensión de las excavaciones, a finales de noviembre de 1932 una comitiva encabezada por el Alcalde acudió a las obras tras una denuncia que advertía sobre el riesgo que corría el edificio a causa de los trabajos que se realizaban. Esta denuncia conllevó que el Ministerio de Instrucción Pública ordenara la paralización de los trabajos. La publicación de una falsa noticia el 28 de diciembre de 1932 en La Voz de Madrid supuso otra muestra del estado de ánimo existente con respecto a las excavaciones. La inocentada inclúa un montaje fotográfico que mostraba un escenario dantesco con el derrumbe de numerosas columnas. Finalmente se procedió al relleno de las excavaciones y al pertinente rebaje del pavimento, aunque "la Comisión Provincial de Monumentos había protestado por esta innovación en su sesión de 29 de diciembre de 1933 "

A pesar de las pequeñas dotaciones económicas asignadas, en 1934 se continuó la investigación en el Patio de los Naranjos, sacando a la luz restos de otro edificio con elementos visigodos asociados, las cimentaciones del alminar de Hisham I y el muro norte del Patio anterior a Abd alRahman II. Se conserva un croquis dibujado por Samuel de los Santos, director del Museo Arqueológico de Córdoba en ese momento, en el que se recogen los restos de las construcciones aparecidas. Esta había sido la única referencia de estos restos hasta el reciente hallazgo, a cargo de FernándezPuertas, del negativo de una fotografía de un dibujo de Hernández sobre estos restos, aunque sin datos para su ubicación en el Patio ${ }^{9}$. El arqueólogo Pedro Marfil ha defendido la posibilidad de que San Vicente se tratara de un complejo constructivo compuesto por diferentes edificaciones, incluyendo las halladas bajo la sala de oración de Abd al-Rahman I y las del Patio ${ }^{10}$. En último término, Bermúdez Cano ha intentado determinar la funcionalidad de las construcciones identificadas por

${ }^{5}$ Hernández no dejó escrita memoria de esta excavación. La inscripción existente en uno de estos ladrillos sirvió al epigrafista para realizar esta datación.

${ }^{6}$ Carta de José Ma Rodríguez Cano a Manuel Gómez-Moreno, 7 de noviembre de 1932, AGM, correspondencia 1932.

7 Así lo demuestra la numerosa correspondencia de arquitectos como Constantino Candeira, Rodríguez Cano o Alejandro Ferrant conservada en el Archivo Gómez-Moreno.

${ }^{8}$ Nieto Cumplido, 1998: 38.

${ }^{9}$ Fernández-Puertas, 2009: 145.

${ }_{10}$ Marfil Ruiz, 2000: 174.

Arch. esp. arte, LXXXVIII, 349, ENERO-MARZO 2015, 1-18 ISSN: 0004-0428, eISSN: 1988-8511, doi: 10.3989/aearte.2015.01 


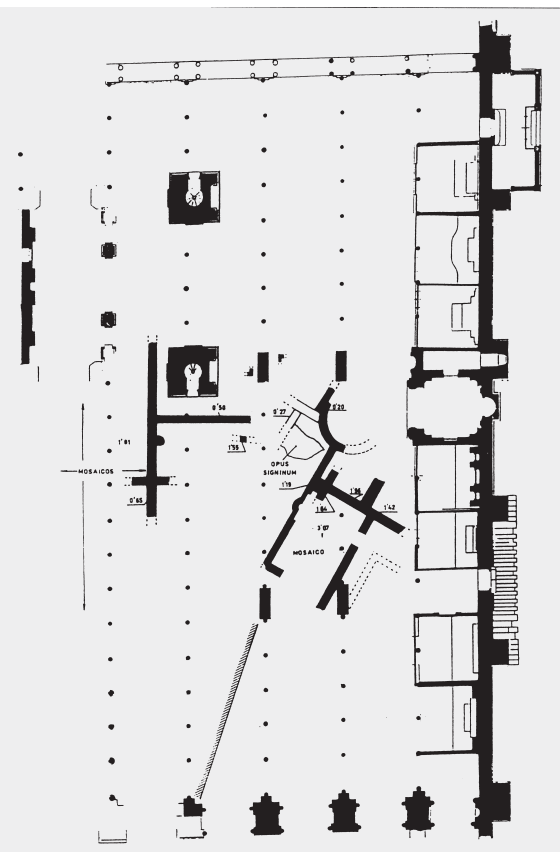

Fig. 3. Pedro Marfil. Localización de los restos arqueológicos encontrados por Félix Hernández. En Marfil Ruiz, 2000: 158.

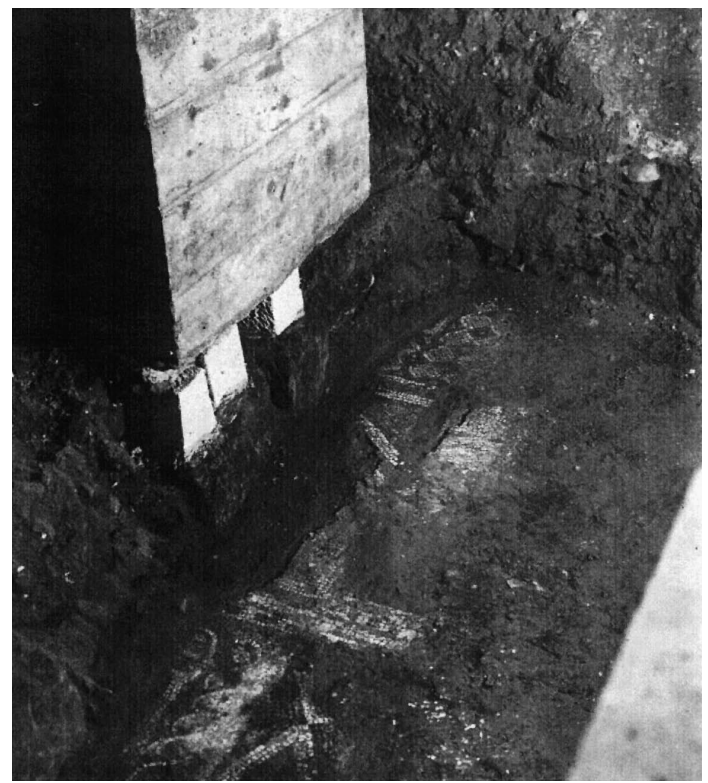

Fig. 4. Mosaico hallado en la excavación en las naves occidentales de Abd al-Rahman I y dado de hormigón de recalzo de la cimentación de la columna, 1932. Museo Arqueológico de Córdoba, Archivo Félix Hernández, PO-47.

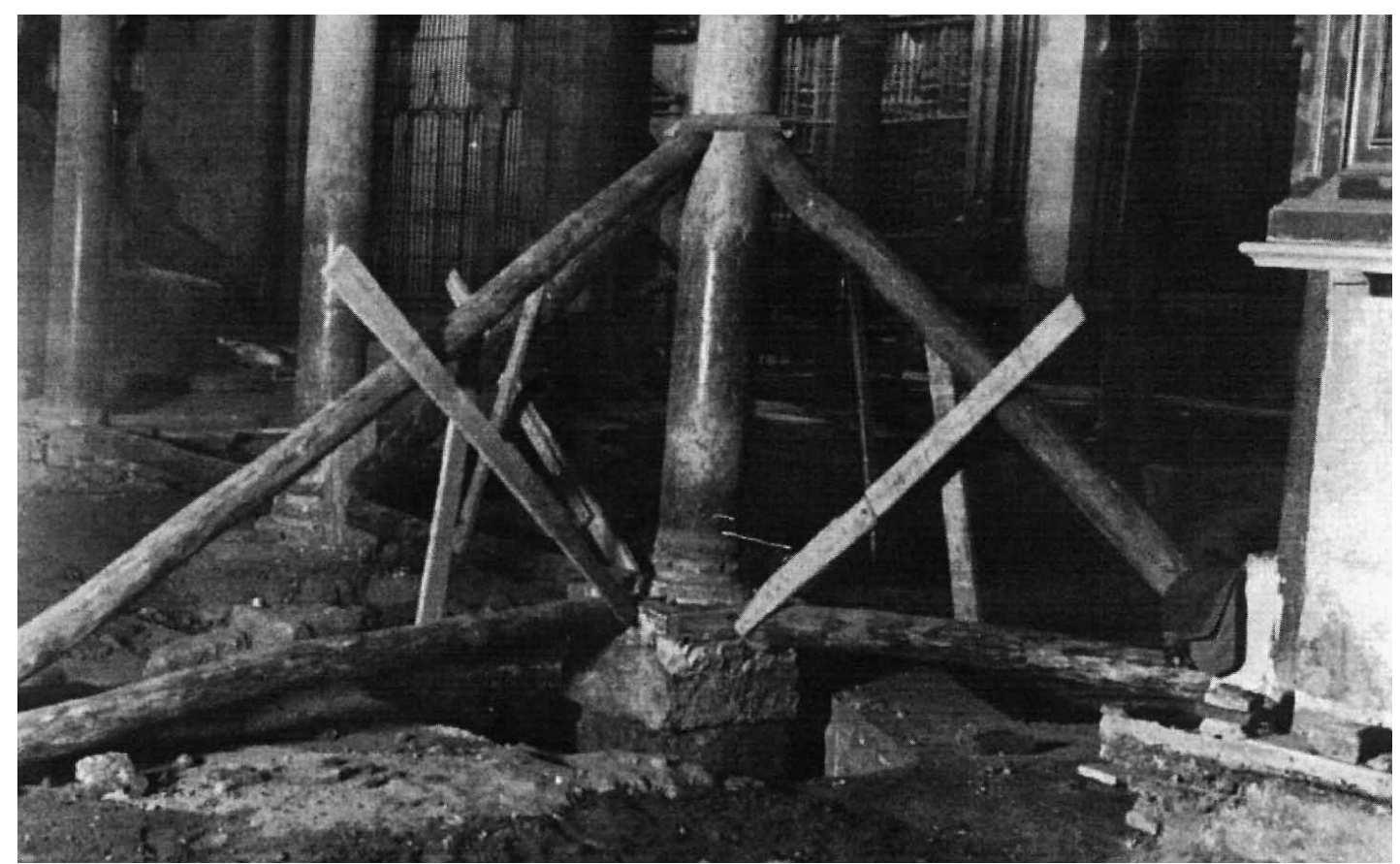

Fig. 5. Apeo provisional de una de las columnas afectadas por las excavaciones realizadas en las naves occidentales de Abd al-Rahman I, 1932. Museo Arqueológico de Córdoba, Archivo Félix Hernández, PO-47.

Arch. esp. arte, LXXXVIII, 349, ENERO-MARZO 2015, 1-18

ISSN: 0004-0428, eISSN: 1988-8511, doi: 10.3989/aearte.2015.01 
Fernández-Puertas, sosteniendo que se trata de un atrium destinado a la episcopalis audientia, pero sin conseguir nuevos datos necesarios para situar exactamente las construcciones investigadas en el Patio ${ }^{11}$, aunque aporta un esquema de conjunto (fig. 6).

\section{Hernández y su trabajo como arquitecto jefe de zona en el edificio}

En abril de 1936 se produjeron una serie de cambios en la organización de la protección del patrimonio forzados tanto por una nueva división territorial como por la renuncia de Emilio Moya. La Junta del Tesoro acordó que Rodríguez Cano sustituyera a Moya en la zona central y de esta forma Hernández se encargaría de lo que hasta ahora había dirigido Rodríguez Cano desde 1930. Finalmente su nombramiento se produjo con fecha 6 de mayo de $1936^{12}$.

El 8 de julio de 1936, pocos días antes del Alzamiento del General Franco, Félix Hernández firmó como arquitecto conservador de la zona $\mathrm{V}$ su primer proyecto de restauración en el edificio ${ }^{13}$. La memoria de este ambicioso proyecto proponía tres actuaciones. En primer

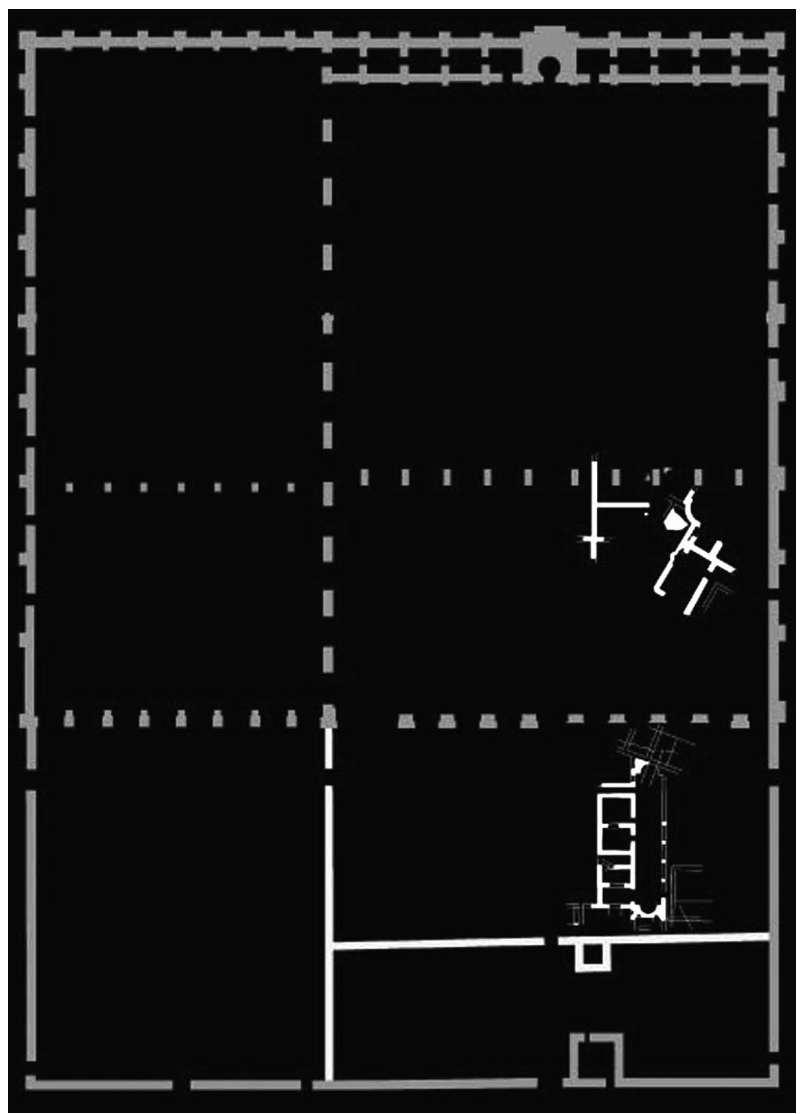

Fig. 6. José Manuel Bermúdez Cano. Excavaciones de don Félix Hernández: localización de las estructuras tardoantiguas. En Bermúdez Cano, 2010: 322. lugar, la continuación de la exploración de las partes del subsuelo no reconocidas en la zona de Abd al-Rahman I, con el consecuente cinchado de hormigón armado entorno a las cimentaciones y el rebaje del nivel de pavimento en este sector. En segundo lugar, la finalización de las excavaciones que se habían venido desarrollando en el Patio de los Naranjos. Y por último, la sustitución de cubiertas y techumbres en la zona de Almanzor ante el evidente riesgo de incendio. Era preciso hacer desaparecer ese riesgo, siguiendo el proceso de cambio de las cubiertas de madera de par e hilera por cerchas metálicas iniciado por Velázquez Bosco. En este caso, Hernández propuso modificar el tirante colocando en su lugar una barra quebrada que facilitaba el registro del espacio bajo la cubierta y también sustituir las bovedillas que formaban el tablero por soleras de hormigón. En cuanto a las techumbres, era necesaria su reposición para la devolu-

\footnotetext{
${ }^{11}$ Bermúdez Cano, 2010: 329.

${ }_{12}$ Gaceta de Madrid, n 132, 11-V-1936: 1385.

${ }_{13}$ Proyecto de Restauración de la Mezquita, 8 de julio de 1936, Museo Arqueológico de Córdoba, Archivo Félix Hernández, Córdoba (AFH), caja FH6, carpeta 3.
}

Arch. esp. arte, LXXXVIII, 349, ENERO-MARZO 2015, 1-18 ISSN: 0004-0428, eISSN: 1988-8511, doi: 10.3989/aearte.2015.01 
ción a este espacio de una geometría precisa, aunque era improcedente la repetición de la decoración. Como reconocía Hernández, las bóvedas encamonadas barrocas habían alterado profundamente la configuración originaria del monumento, dándole un aspecto en cierto modo inconciliable con el que hubo de ser. La solución propuesta consistía en una serie de vigas y una solera de hormigón armado forradas con un revestimiento de madera, de tal forma que fuera imposible la propagación del fuego. Esta actuación propuesta se centraba en la zona de Almanzor, quedando pendiente el estudio y examen de la mezquita de Abd al-Rahman I y II.

Esta ambiciosa intervención contaba con un presupuesto de 350.000 ptas y se correspondía con el Proyecto de Ley para la ejecución de un Plan de obras, excavaciones y adquisiciones de edificios y terrenos con destino a Monumentos del Tesoro Artístico Nacional presentado por el Gobierno a las Cortes en mayo de $1936^{14}$. Este Plan pretendía terminar con el goteo de pequeñas dotaciones económicas que permitía la ejecución de obras sin necesidad de aprobación de proyecto, según quedaba recogido en la Ley de 1933. El artículo 1 del Proyecto de Ley enumeraba la relación de intervenciones previstas, consignándose para la Mezquita de Córdoba un presupuesto de 350.000 ptas, concretando que "en Córdoba se precisa la sustitución de la techumbre de la Mezquita, que es moderna y de madera, por otra de hierro y cemento que evite los peligros de un incendio" ${ }^{15}$. Si atendemos a la fecha en que debió ser realizado el informe que sirvió de base para la propuesta de Plan de obras del Gobierno, parece claro que el responsable fue José $\mathrm{M}^{\mathrm{a}}$ Rodríguez Cano, aunque es igualmente lógico suponer que contó con la ayuda de su auxiliar. No es de extrañar por tanto, la coincidencia de objetivos y de presupuesto entre el Plan y este primer proyecto firmado por Hernández.

No se ha encontrado ningún documento oficial en el que figure tal dotación, aunque hay constancia de la aprobación por parte de la Junta del Tesoro en julio de 1936 de otros trabajos, todos ellos de menor cuantía, incluido uno en la Mezquita ${ }^{16}$. Indudablemente, el estallido de la Guerra Civil supuso un giro inesperado en muchos aspectos, anulando la posibilidad de que se llegara a aprobar esta actuación y paralizando cualquier tipo de investigación arqueológica, al ordenar el General Cascajos el relleno inmediato de las excavaciones del Patio de los Naranjos ${ }^{17}$.

Una vez finalizada la Guerra, quedó establecida la estructura definitiva de la Comisaría del Servicio de Defensa del Patrimonio Artístico Nacional (SDPAN) de la que dependerán los Comisarios de Zona, los arquitectos conservadores y los auxiliares. En abril de 1940, Félix Hernández fue confirmado en el cargo ${ }^{18}$, pasando a corresponderle la zona $6^{\mathrm{a}}$ en la que se encontraban Sevilla, Córdoba, Huelva, Cádiz, Badajoz, Tenerife, Las Palmas y las colonias en África ${ }^{19}$. Hemos podido determinar su labor en el edificio contrastando los datos que ofrecen los 19 expedientes conservados en el Archivo General de la Administración sobre sus proyectos en la Mezquita y lo recogido por el Anuario de Estudios Arabistas Al-Mulk ${ }^{20}$.

${ }^{14}$ Gaceta de Madrid, no 131, 10-V-1936: 1355.

${ }_{15}$ Gaceta de Madrid, no 131, 10-V-1936: 1355.

${ }^{16}$ Es el caso de la ejecución de los trabajos necesarios para la consolidación de elementos decorativos del sector incorporado al oratorio de la Mezquita de Córdoba en la parte construida en la época de Hisham II, por importe de 10.000 ptas. Gaceta de Madrid, nº 201, 19-VII-1936: 725.

${ }^{17}$ Ciriaco Cascajos era la máxima autoridad militar en la ciudad de Córdoba tras la toma de ésta por parte del bando sublevado.

${ }^{18} B O E, \mathrm{n}^{\circ}$ 134, 13-V-1940: 3280-3281.

$19 B O E, \mathrm{n}^{\mathrm{o}} 73,13-\mathrm{III}-1940: 1777$.

${ }^{20}$ Al-Mulk fue editado por el Instituto de Estudios Califales como suplemento al Boletín de la Real Academia de Córdoba. Tanto en el primer número editado en 1960 como en el segundo de 1961 y 1962 se hacía un repaso detallado de las intervenciones realizadas en los monumentos árabes de Córdoba.

Arch. esp. arte, LXXXVIII, 349, ENERO-MARZO 2015, 1-18

ISSN: 0004-0428, eISSN: 1988-8511, doi: 10.3989/aearte.2015.01 
No fue hasta mayo de 1941 cuando realizó su primer proyecto para la restauración de la Mezquita en esta nueva etapa ${ }^{21}$. Este trabajo consistió fundamentalmente en la puesta al día del edificio tras la inactividad sufrida desde 1936. Se atendían numerosos repasos en cubiertas, así como en las instalaciones fundamentales para evitar el riesgo de incendio -pararrayos, motobombas e instalación eléctrica-, continuándose el rebaje del nivel del pavimento paralizado en 1936 (fig. 7). Esta cuestión se convirtió en motivo de debate público, puesto que fue objeto de una moción presentada por Rafael Castejón ante la Comisión Provincial de Monumentos en diciembre de $1943^{22}$. Castejón dudaba del buen funcionamiento de las rampas necesarias para ingresar al edificio y argumentaba que no se debía autorizar el rebaje del nivel sin aducir un dato ni publicar una opinión que apoyara tal determinación, máxime cuando tampoco se podía confirmar la consecución exacta del nivel primitivo. Hernández centró la defensa de su solución en que mejoraba las proporciones del edificio y la visibilidad de la mayoría de las basas de las columnas, aprobando finalmente la Comisión la continuación de estas obras.

En este primer proyecto también se planteó la relación que debía existir entre la sala de oración y el patio. De la misma forma que hiciera Velázquez Bosco, Hernández buscó la recuperación de la iluminación natural original de la sala a través de los arcos que conformaban la fachada

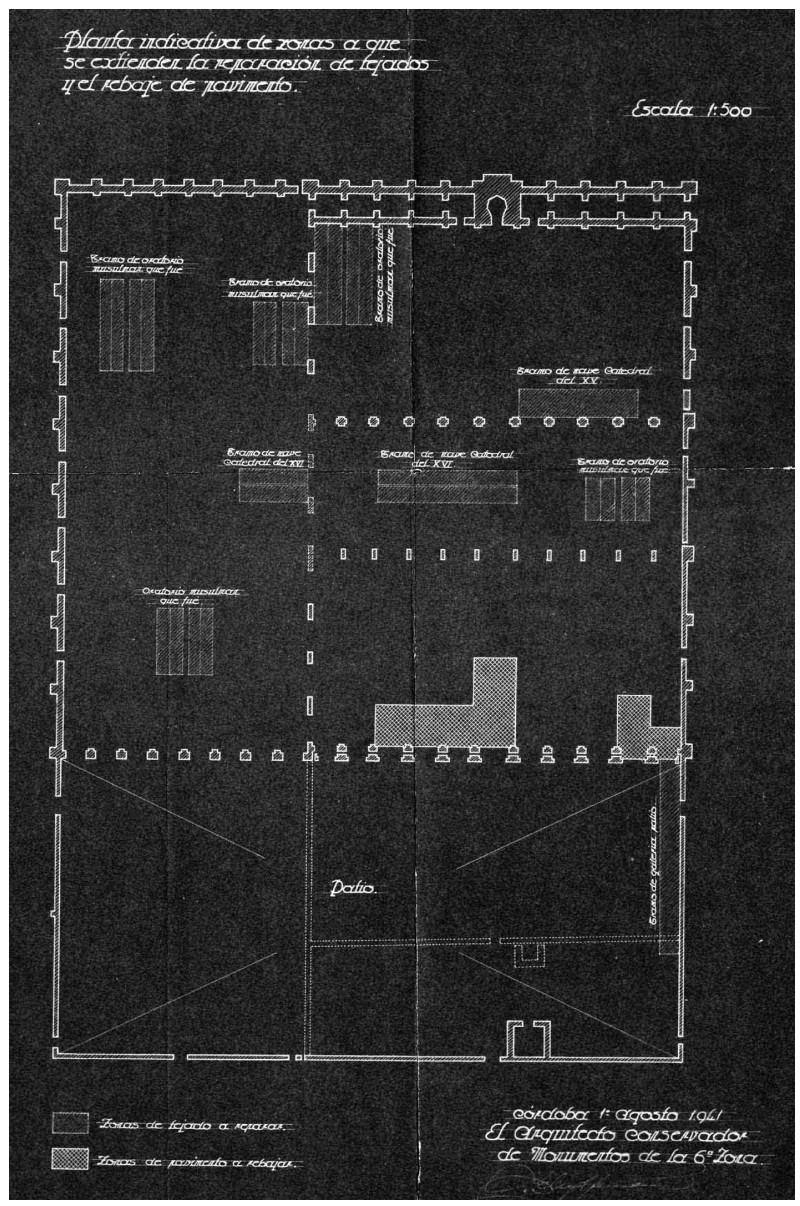

Fig. 7. Félix Hernández. Planta indicativa de zonas a que se extiende la reparación de tejados y el rebaje de solería, escala 1:500, 1941. Instituto del Patrimonio Cultural de España, Planoteca, 07102. al patio y que no contaban con capillas adosadas. Para tal fin, incluyó la ejecución de una cristalera como cierre de una de las naves a fin de devolver esa iluminación originaria. Esta cristalera debía contar con un trazado geométrico de carácter primario sin ninguna influencia musulmana en la composición. En concreto, propuso un armazón en forma de cuadrícula, en línea con lo anteriormente proyectado por Velázquez Bosco, aunque en este caso no hubiera ningún segmento curvo. Los cuadros resultantes se completaron con vidrios de aguas con una lacería geométrica. El agotamiento del presupuesto de este primer proyecto hizo que no se ejecutara.

${ }^{21}$ Proyecto de obras de conservación y restitución en parte a su disposición originaria en la Mezquita de Córdoba, 7 de mayo de 1941, Archivo General de la Administración, Alcalá de Henares (AGA), fondo (5) 14.2, signatura 31/06020.

${ }^{22} \mathrm{El} \mathrm{n}^{\circ} 2$ de Al-Mulk publicó la moción presentada por Castejón y el informe contestación de Hernández. 


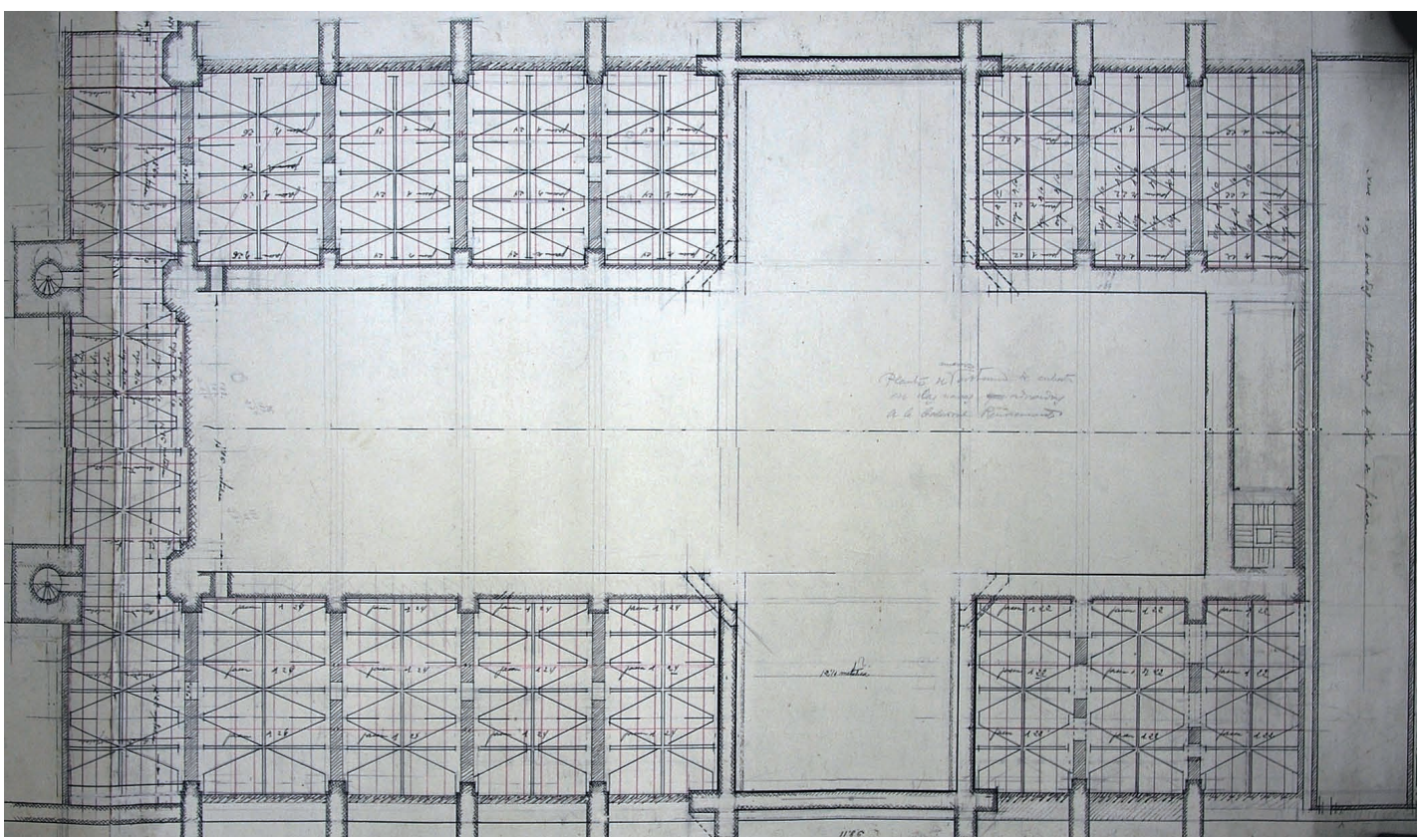

Fig. 8. Félix Hernández. Planta indicativa del esquema estructural propuesto para las cubiertas de las naves contiguas al Crucero, escala 1:50, 1944. Museo Arqueológico de Córdoba, Archivo Félix Hernández, plano $\mathrm{n}^{\circ} 50$.

El siguiente proyecto, presentado en 1942, recogía todo lo no ejecutado en el primer proyecto e incorporaba las primeras actuaciones de resanado de elementos de pétreos a base de morteros de cementos, arena y piedra machacada ${ }^{23}$. Este procedimiento fue empleado en la reparación de varias portadas y de diferentes machones del Patio de los Naranjos. Hernández demostraba una gran confianza en esta solución que era rápida, sencilla y con buenos resultados aparentes, incluyendo en los pliegos de condiciones dosificaciones específicas para cada tipo de situación.

El proyecto presentado en 1944 insistía en las tareas de mantenimiento y en todas aquellas iniciadas anteriormente y no completadas, tales como la ejecución de la cristalera, el resanado de sillares o el rebaje del pavimento en las naves orientales de la mezquita de Abd al-Rahman ${ }^{24}$. De nuevo, la obsesión por reducir el riesgo de incendio determinó la propuesta de actuación en cubiertas, afectando en este caso a las que se encontraban alrededor del Crucero. Hernández pretendía cambiar la estructura de madera por otra metálica compuesta por una grandes jácenas en el sentido de las aguas y una viguetas metálicas perpendiculares a estás, aludiendo a la incombustibilidad de la solución de Velázquez Bosco en la ampliación de al-Hakam II como ejemplo a seguir (fig. 8). Esta ambiciosa intervención no fue finalmente ejecutada hasta la década de los 60.

${ }^{23}$ Proyecto de obras a ejecutar en la Mezquita de Córdoba para la normal conservación del monumento, restitución de parte de él a su disposición originaria y adecuada presentación del mismo, 14 de agosto de 1942, AGA, fondo (5) 14.2, signatura 31/06020.

${ }^{24}$ Proyecto de obras a efectuar en la Mezquita de Córdoba para la consolidación, restitución de parte de ella a su disposición originaria y adecuada presentación del tesoro catedralicio que en dicho monumento se custodia, 29 de febrero de 1944, AGA, fondo (3) 115, signatura 26/00386.

Arch. esp. arte, LXXXVIII, 349, ENERO-MARZO 2015, 1-18

ISSN: 0004-0428, eISSN: 1988-8511, doi: 10.3989/aearte.2015.01 


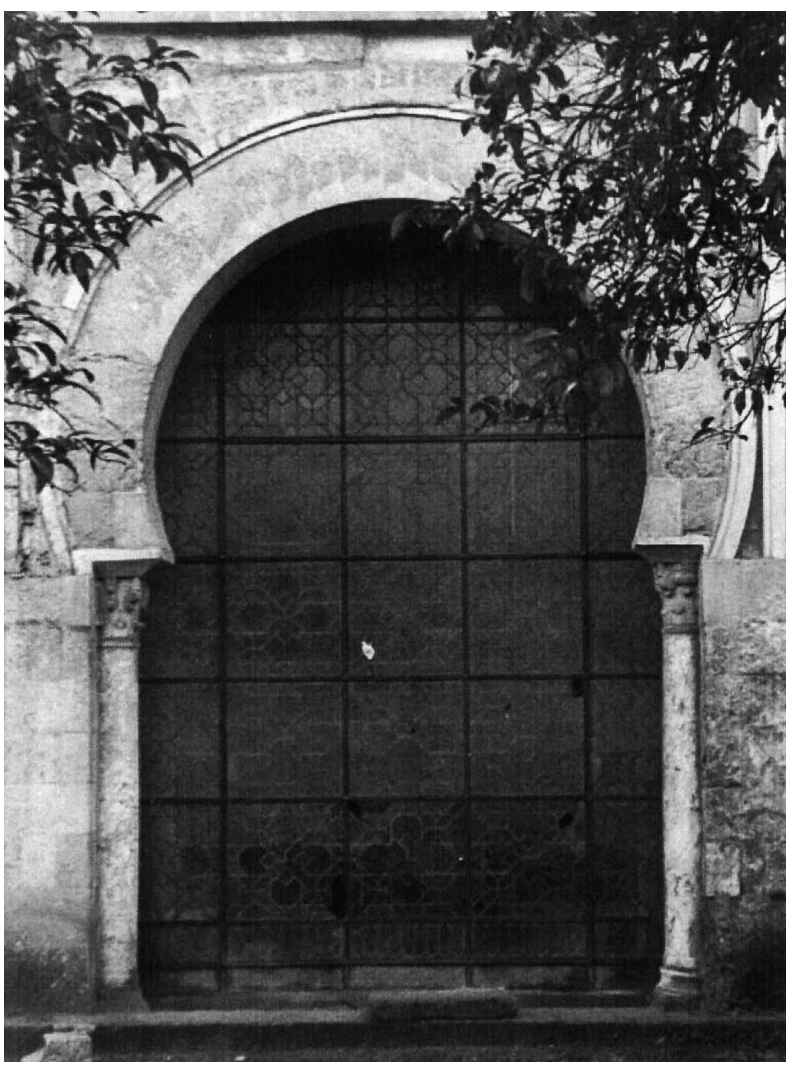

Fig. 9. Estado definitivo de la vidriera realizada en la fachada al patio de la nave 16, 1946. Museo Arqueológico de Córdoba, Archivo Félix Hernández, PO-13/3.
En cambio, se terminó la cristalera que cerraba la nave 16 al Patio (fig. 9), incluyéndose en el proyecto de 1946 otra para continuar así el proceso de recuperación de la iluminación original, aunque tampoco llegó a realizarse ${ }^{25}$.

En los 50 Hernández presentó un total de 7 proyectos que supusieron la confirmación de la mayor parte de estos primeros planteamientos. Se insistía reiteradamente en la necesidad de la limpieza y repaso de las cubiertas con especial interés en las canales y los muretes de apoyo, en el resanado de sillería, la reposición de pavimentos en la ampliación de Almanzor y en la ejecución de la solución metálica para las cubiertas que bordean al Crucero. Sin embargo, en el proyecto elaborado en 1954 aparece como novedad la consolidación y el resanado de las bóvedas encamonadas barrocas que dos décadas antes se planteaba desmontar ya que se alejaban de la configuración original del espacio hispanomusulmán ${ }^{26}$. Esta reconsideración se vio confirmada al incluirse en otros proyectos posteriores.

El comienzo de la década de los 60 supondrá el principio de la etapa final de uno de los trabajos de investigación que acompañaron a Félix Hernández en buena parte de su etapa en el edificio.

Será en diciembre de 1960 cuando envíe a Gómez-Moreno su escrito sobre $E l$ codo ${ }^{27}$. En cuanto a las obras realizadas en la Mezquita-Catedral, cabe destacar que la existencia de 7 expedientes en los que, además de las preceptivas obras de estricto mantenimiento, se acometía de manera definitiva la sustitución por fases de las cubiertas que se encontraban alrededor del Crucero de la Catedral. Hernández irá sustituyendo paulatinamente las cubiertas existentes por otras realizadas a base de viguetas de hormigón armado, comenzando por la cubierta de una de las naves situadas al $\mathrm{NO}^{28}$. La vieja pretensión de construir unas cubiertas incombustibles se hacía finalmente realidad en el edificio. Pero en este caso, la existencia de bóvedas góticas en estos tramos que sirven de encuentro entre la intervención del Crucero y el resto del edificio, redujo el problema al plano de las

${ }^{25}$ Esta cristalera perduró hasta 1972, año en que la Dirección General construyó nuevas celosías de madera y vidrio para los huecos de las naves $15,16,17$ y 18 .

${ }^{26}$ Proyecto de obra a verificar para la conservación y más adecuada presentación de la Mezquita de Córdoba, 29 de marzo de 1954, AGA, fondo (3) 115, signatura 26/00387.

${ }^{27}$ Hernández Giménez, 1961.

${ }^{28}$ Proyecto de obra de conservación y para más adecuada presentación a llevar a cabo en la Mezquita de Córdoba, 22 de mayo de 1959, AGA, fondo (3) 115, signatura 26/00345.

Arch. esp. arte, LXXXVIII, 349, ENERO-MARZO 2015, 1-18 ISSN: 0004-0428, eISSN: 1988-8511, doi: 10.3989/aearte.2015.01 


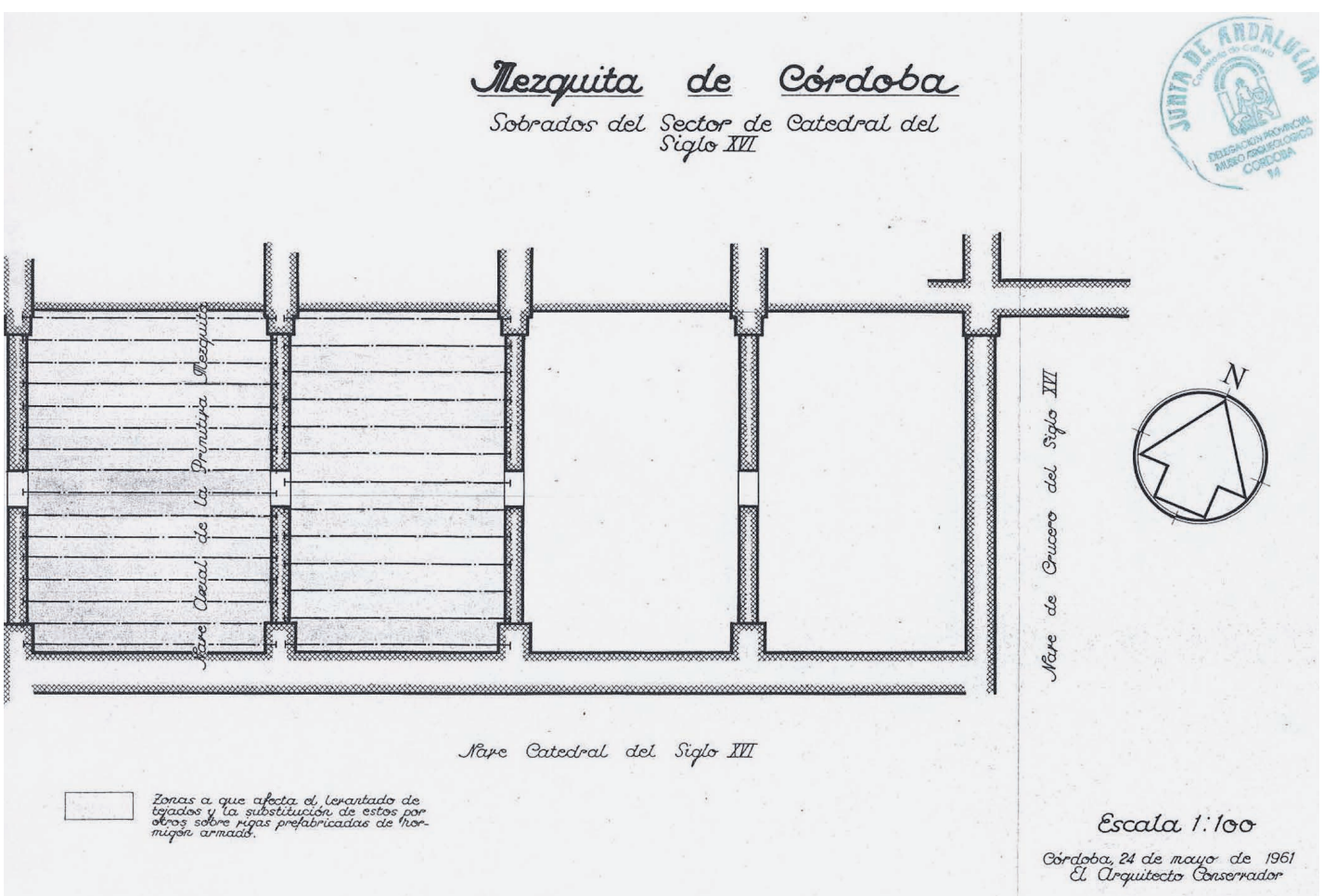

Fig. 10. Félix Hernández. Planta indicativa sobre actuaciones en cubierta en las naves al SO del Crucero, escala 1:100, 1961. Museo Arqueológico de Córdoba, Archivo Félix Hernández, carpeta 6-4.

cubiertas. Esta reforma se ejecutó finalmente con una solución más sencilla a la planteada en 1944, sin elementos intermedios, colocando una serie de viguetas de hormigón armado de $24 \mathrm{~cm}$ de canto que cubrían las naves siguiendo el perfil de la cubierta, quedando los entrevigados definidos por unas pequeñas bóvedas de ladrillo. Las obras se fueron acometiendo en pequeños sectores, acordes con las ajustadas dotaciones presupuestarias, siguiendo por el NO (fig. 10), pasando a las cubiertas orientadas a S y terminando con las cubiertas del sector NE en $1964^{29}$. Tras estas intervenciones, la actividad de Hernández se centrará en el estricto mantenimiento hasta que la Dirección General de Arquitectura comience a invadir sus competencias a partir de 1972.

\section{Criterios disciplinares}

La Carta de Atenas y la búsqueda de la espacialidad original

En 1933 fue aprobada la Ley de defensa, conservación y acrecentamiento del Tesoro Artístico Nacional, cuyos criterios estaban en relación con los planteamientos y recomendaciones de la Carta de Atenas de 1931. Según González-Varas, la presencia de Torres Balbás en Atenas facilitó

${ }^{29}$ Proyecto de obra de mera conservación a llevar a cabo en la Mezquita de Córdoba, 3 de abril de 1964, AGA, fondo (3) 115 , signatura 26/00349.

Arch. esp. arte, LXXXVIII, 349, ENERO-MARZO 2015, 1-18

ISSN: 0004-0428, eISSN: 1988-8511, doi: 10.3989/aearte.2015.01 
la difusión de estos principios internacionales en España ${ }^{30}$. Entre las conclusiones del encuentro de Atenas se encontraba la tendencia general a abandonar las restituciones integrales, apostando por las obras de mantenimiento regular y permanente. El artículo 19 de la Ley recogía esta consideración, quedando proscrito todo intento de reconstrucción de monumentos, "procurándose por todos los medios de la técnica su conservación y consolidación, limitándose a restaurar lo que sea absolutamente indispensable y dejando siempre reconocibles las adiciones"31.

No se establecían diferencias notables de carácter administrativo con la situación anterior a 1933, manteniendo la estructura de zonas con los arquitectos jefes a su cargo. Sin embargo, hubo escasos medios económicos que dificultaron su aplicación, realizándose pequeñas intervenciones, de consolidación en la mayoría de los casos. La posibilidad de ejecutar obras de carácter urgente por un importe máximo de 10.000 ptas sin necesidad de contar con la aprobación de un proyecto, tuvo como consecuencia un gran número de intervenciones menores que no conseguían afrontar adecuadamente la conservación de determinados. El Plan de obras de 1936 supuso una gran oportunidad para intervenir en la Mezquita de Córdoba con un presupuesto acorde a las pretensiones. Este primer proyecto fue sin duda el más ambicioso de cuantos realizó y en el que estableció como criterio preferente la recuperación de la espacialidad original en base a una nueva y original techumbre interior.

Aunque finalmente no se realizó, el descubrimiento de este texto demuestra la estrecha colaboración que debió existir entre Rodríguez Cano y Hernández. De lo contrario, Hernández hubiera introducido algún cambio en el proyecto que lo diferenciara de las intenciones recogidas en el Plan. Sin embargo, continuó con idénticos criterios a los utilizados anteriormente, lo que confirma las influencias de la restauración científica en el desarrollo de las labores de protección del edificio, criterios que habían determinado en buena medida el marco normativo desarrollado en la etapa republicana. La Carta de Atenas, que pretendía evitar las reintegraciones en estilo, aceptaba en su artículo $5^{\circ}$ los recursos que facilitaba la técnica moderna para la consolidación de edificios, debiendo quedar estos medios de refuerzo disimulados para no alterar el carácter del edificio a restaurar. La nueva estructura de cubierta propuesta resultaba invisible desde el interior del Templo y además respondía mejor a los efectos del fuego. Por lo tanto, la solución parecía quedar justificada por su eficacia en la protección contra incendios, al tiempo que se encontraba avalada por el marco normativo vigente y por el entendimiento disciplinar del momento.

Esta propuesta para realizar unas cubiertas incombustibles se complementaba con una techumbre interior organizada en base a unos elementos de hormigón recubiertos por un revestimiento de madera. Esta segunda barrera perseguía la recuperación de la espacialidad original, prevaleciendo el restablecimiento de la imagen del siglo X. A pesar de que el respeto por la obra histórica y artística del pasado también estaba recogido por la Carta de Atenas, Hernández justificaba la eliminación de las bóvedas barrocas al considerar que su ejecución había tergiversado notablemente el espacio hispanomusulmán. Sin lugar a dudas, la labor de recuperación de lo original que había realizado anteriormente Velázquez Bosco en la ampliación de al-Hakam II suponía un antecedente cuya influencia era difícilmente evitable. La sola idea de recuperar en la práctica totalidad del edificio ese espacio horizontal en penumbra era tan poderosa, que no propiciaba un ambiente de respeto hacia las frágiles y luminosas bóvedas de cañizo y yeso, cuya imagen estaba tan alejada de esa espacialidad buscada.

En el proyecto de 1942 quedó reflejado claramente el criterio fundamental que había de regir las intervenciones: "en su materialidad, las obras consignadas se efectuarán con absoluto respeto a la disposición originaria del monumento, o donde esta falte, de la que hubo de reemplazarla

\footnotetext{
${ }^{30}$ González-Varas Ibáñez, 1999: 469.

${ }^{31}$ Gaceta de Madrid, n 145, 25-V-1933: 1395.
}

Arch. esp. arte, LXXXVIII, 349, ENERO-MARZO 2015, 1-18 ISSN: 0004-0428, eISSN: 1988-8511, doi: 10.3989/aearte.2015.01 
siempre que sea de reconocido interés artístico"32. Estas líneas se convertirán en el recurrente cierre de la mayoría de las memorias pertenecientes a los proyectos conservados en el Archivo General de la Administración, resultando un invariante de sus planteamientos. A pesar de que Félix Hernández expresaba su respeto no sólo a las partes originales sino también a todas aquellas que tuvieran interés, la insistencia en la recuperación de la imagen islámica interior del edificio forzó el sacrificio de algunos elementos arquitectónicos que distorsionaban esa imagen, produciendo en ocasiones un alejamiento de ese respeto a las páginas de la historia del edificio.

Aunque no llegó a ejecutar esta propuesta en el edificio, Hernández dejó numerosas muestras de su confianza en la solución, puesto que aparece reiteradamente en numerosos expedientes. Esta confianza también se refleja en la ejecución de soluciones idénticas en otros edificio a su cargo, como fue el caso de la restauración del Salón Rico de Madinat al-Zahra en 1953 en el que se rehízo la techumbre colocando viguetas de hormigón para su posterior revestimiento. A la necesidad de construir unas cubiertas incombustibles se unió, de nuevo, la intención de recuperar la espacialidad original. De hecho, esta intención aparece incluso en el título de algunos de los proyectos consultados.

Paradójicamente, los cambios de toda índole que trajo el final de la Guerra Civil no modificaron el escenario normativo básico de la protección del patrimonio. De esta forma, el trabajo de Hernández se desarrolló en el marco de una Ley conocida en su trabajo anterior. Tampoco varió la carestía de medios, en este caso justificada por la dura posguerra que vivió el país. En contraposición a la labor de Regiones Devastadas, la Dirección General de Bellas Artes y los arquitectos de zona siguieron realizando una labor tendente a la reparación y a la consolidación de acuerdo con el espíritu y la letra de la ley. En ningún caso las intervenciones estuvieron definidas por unas directrices fijadas por la Comisaría General. Más bien, el bagaje de cada uno de los arquitectos fue el que determinó la forma de actuar y en el caso de Hernández la influencia de Gómez-Moreno y Torres Balbás lo mantuvieron próximo a los criterios científicos.

La idea de la recuperación de lo original subyace en otro tipo de trabajos, como en las obras de rebaje del nivel de pavimento realizadas en la sala de oración de Abd al-Rahman I. El hecho de que las basas de las columnas hubieran quedado por debajo del nivel de pavimento de Velázquez Bosco y el hecho de que aparecieran diferentes huellas de pavimentos en las excavaciones arqueológicas justificaban la búsqueda del nivel original. Estas obras fueron iniciadas por Rodríguez Cano y Hernández como auxiliar en 1932 y continuadas por Hernández en solitario en sucesivas intervenciones en la década de los 40 , completando la huella de la mezquita fundacional. Conocimientos posteriores habrían de determinar la composición del suelo originario y el uso de esteras para el forro de los fustes, por lo que el afán de llegar a una configuración original dejando vistas las basas quedaba carente de importancia. Sin embargo, debemos tener en cuenta que con esta actuación se vio mejorada la apreciación de los límites de la primera mezquita, ahondando en el valor didáctico que debía tener toda intervención según Hernández.

\section{El empleo de materiales modernos}

Como hemos comentado, la Carta de Atenas aprobó el empleo juicioso de los recursos de la técnica moderna para el caso de consolidaciones de edificios, siempre que su conservación dependiera de ello. El caso más claro de aplicación de este criterio fue el recalzo de la cimentación de

${ }^{32}$ Proyecto de obras a ejecutar en la Mezquita de Córdoba para la normal conservación del monumento, restitución de parte de él a su disposición originaria y adecuada presentación del mismo, 14 de agosto de 1942, AGA, fondo (5) 14.2, signatura 31/06020.

Arch. esp. arte, LXXXVIII, 349, ENERO-MARZO 2015, 1-18

ISSN: 0004-0428, eISSN: 1988-8511, doi: 10.3989/aearte.2015.01 
las columnas de la mezquita de Abd al-Rahman I con dados hormigón en masa. Esta actuación fue comenzada en el periodo de Rodríguez Cano, pero Hernández continúo afianzando la cimentación.

En la misma línea, se planteará reiteradamente en los proyectos de los años 40 y 50 la elaboración de unas nuevas estructuras para las cubiertas en base a elementos metálicos. En el caso de la Mezquita-Catedral de Córdoba, la existencia de la techumbre interior hacía imposible su visión, resultando una solución adaptada al criterio de utilización disimulada para no alterar el aspecto del edificio a conservar. A pesar de la insistencia, no llegaron a ejecutarse.

Fue finalmente en los años 60 cuando se planteó una necesidad similar, en este caso en las cubiertas existentes alrededor del Crucero. Protegido por la condición de su invisibilidad y amparado en la eficacia y la economía de la solución, Hernández realizó finalmente estas nuevas cubiertas ignorando el sistema constructivo en madera. Sin embargo, el escenario disciplinar en este momento ya había comenzado a alejarse de estos criterios. La década de los 60 se puede considerar como de una etapa de estancamiento en la práctica de la restauración en España tras el impulso reconstructor de la posguerra, pero en el resto de Europa fue el momento para la revisión de los criterios utilizados y el establecimiento de un nuevo marco doctrinal. En 1964 se promulgó la Carta de Venecia que, entre otros objetivos, ampliaba el concepto de monumento considerando su entorno, protegía los valores inherentes al monumento, en especial la confluencia de una instancia histórica y una instancia estética en toda obra de arte y, finalmente, estableciendo la utilización de los sistemas y las técnicas tradicionales como condición previa. A pesar de este nuevo escenario, la actuación desarrollada en la última etapa de Hernández al frente del edificio se mantuvo al margen de estas nuevas consideraciones disciplinares.

El empleo de materiales modernos para atender las consolidaciones llevó a Hernández a utilizar morteros de cemento y piedra pulverizada para la recomposición de pérdidas volumétricas en las fábricas de piedra. En los proyectos se dejaba abierta la posibilidad de labrar nuevas piedras en el caso de que el deterioro fuera muy grande. No en vano, otros compañeros introducían habitualmente nuevas piezas de piedra con labras esquemáticas o incluso con volúmenes sin tallar, consiguiendo una conveniente diferenciación con respecto a lo original. Sin embargo, el empleo de esta forma de recomposición fue absolutamente recurrente, por lo que sólo se pueden justificar desde la confianza plena en estos morteros como material más adecuado y desde la obligada economía de medios de las intervenciones. Podemos equiparar esa confianza en los nuevos materiales con la debió tener Furriel en la restauración del arco de ingreso al mihrab. Sin embargo, el paso del tiempo ha venido a traicionar esa confianza, derivando en mayores deterioros que los que se querían solventar.

Otra muestra de la fe depositada en la capacidad de un material ajeno a la fábrica para resolver cuestiones propias de la intervención fue la ejecución de la cristalera en el arco de la fachada al Patio correspondiente a la nave 16. En esta solución se confirma la convicción de que un cerramiento de vidrio era la solución ideal para intentar reproducir la iluminación original que en la mezquita fundacional estaba únicamente relacionada con la entrada de luz a través de los arcos de la fachada al Patio. La posibilidad que ofrecía la inexistencia de capillas adosadas al cerramiento en las naves occidentales de Abd al-Rahman I permitía tal recuperación. La cristalera realizada atendía a la necesidad de utilizar un lenguaje diferenciado, no relacionado con la arquitectura hispanomusulmana, fruto de su tiempo. Sin duda, la coincidencia con Velázquez Bosco tiene mucho que ver con la idéntica confianza que ambos tenían en los materiales modernos como medio de satisfacer los requerimientos originales.

\section{El deseo de conocimiento y el valor didáctico de las intervenciones}

Hernández fue un excelente arqueólogo y destacó más en el desarrollo de esta faceta que en la práctica de arquitecto restaurador. La gran labor indagatoria llevó aparejada una práctica arquitectónica de la restauración no muy extensa, anteponiendo el rigor en el conocimiento a la ejecu-

Arch. esp. arte, LXXXVIII, 349, ENERO-MARZO 2015, 1-18 ISSN: 0004-0428, eISSN: 1988-8511, doi: 10.3989/aearte.2015.01 
ción de alguna obra que no tuviera las garantías científicas exigibles. Ahora nos resulta más fácil discutir sobre su obra ya que el paso del tiempo ha puesto de manifiesto las técnicas constructivas y los criterios utilizados. De los valores presentes en su trabajo, sin duda, el mayor de ellos fue su inagotable esfuerzo por mejorar el conocimiento del edificio. Félix Hernández fue consciente de las evidentes lagunas que existían y de que no se debía acometer ningún tipo de intervención si no se avanzaba en la investigación con anterioridad. La incesante actividad arqueológica y la investigación de fuentes documentales desarrollada nos han legado el conocimiento vigente del edificio. Todos los hallazgos realizados supusieron la confirmación de un nuevo conocimiento sobre el edificio y, en base a él, las intervenciones de Hernández trataron de mejorar su legibilidad. Este es el concepto más interesante de cuantos maneja. En su opinión, sólo mejorando la lectura del edificio se podían apreciar sus valores fundamentales y en la Mezquita de Córdoba, con esa intrínseca complejidad histórica, esta estrategia se hacía más necesaria aún.

Gracias a las recientes investigaciones de $\mathrm{M}^{\mathrm{a}}$ Pilar Mogollón sobre la restauración monumental de la posguerra en Extremadura entre 1941 y $1957^{33}$ queda comprobado que este afán didáctico en la mejora de la comprensión de los edificios era otro invariante en sus intervenciones. En nuestro caso, la revisión de los proyectos conservados en el Archivo General de la Administración no nos ha ofrecido una visión tan nítida sobre este particular como en el caso de los proyectos extremeños. Sin embargo, el estudio de las obras realizadas en el edificio deja entrever esta búsqueda de la mejora de la lectura. Hoy podemos leer la mezquita de Abd al-Rahman I gracias a su huella a distinta cota, identificamos los límites de las ampliaciones, el patio primitivo y el alminar de Hisham I o incluso podemos comprobar cómo era el alminar de Abd al-Rahman III bajo el forro del siglo XVII, prevaleciendo siempre el sentido didáctico de la intervención.

Como complemento a su actividad investigadora y también como herramienta para afianzar el conocimiento del edificio, Hernández se planteó la elaboración de un levantamiento completo de la Mezquita-Catedral. Para tal fin, consideró el dibujo de tres grandes formatos de papel tela, contando con la ayuda de su discípulo Manuel Ocaña. La ejecución de cada hoja fue extremadamente escrupulosa, lo que le llevaba a dibujar siempre en la misma época del año para evitar que las diferentes deformaciones del papel condujeran a algún error. La primera de las hojas reflejaba la sala de oración de Abd al-Rahman I y II y las arcadas correspondientes de la ampliación de Almanzor. El segundo formato incluía la obra de al-Hakam II y el resto de la zona de Almanzor, mientras que el tercero iba a reflejar el Patio. Finalmente, sólo terminó las dos primeras hojas del levantamiento que fueron donadas al Cabildo Catedral de Córdoba tras su muerte ${ }^{34}$.

Nada identifica mejor a un arquitecto que sus dibujos, expresión directa de sus planteamientos y sus inquietudes. Por ese motivo, queremos hacer un breve comentario sobre dos de ellos conservados en el Archivo de Hernández por su capacidad para reflejar nítidamente su forma de trabajo. Se ha conseguido rescatar una planta completa del edificio dibujada a lápiz, repleta de anotaciones, correcciones y triangulaciones de comprobación (fig. 11). En el plano conviven múltiples líneas y anotaciones que son las respuestas a las preguntas que Hernández hace al edificio sobre su construcción. No en vano, la elaboración de la planimetría es también una investigación sobre el edificio. $\mathrm{Y}$ en ese sentido, la pulcritud y el rigor debían guiar la toma de datos. Todas las medidas eran comprobadas en innumerables ocasiones por Hernández y Ocaña ${ }^{35}$. El segundo dibujo recuperado es igualmente muestra del proceso de trabajo (fig. 12). Podíamos afirmar que se trata más bien de una

\footnotetext{
${ }^{33}$ Mogollón Cano-Cortés, 2011.

${ }^{34}$ El Cabildo las puso a disposición de Gabriel Ruiz Cabrero una vez que se hizo cargo de los trabajos de restauración en el edificio. Éste completó el levantamiento dibujando con precisión el Patio de los Naranjos en su primer trabajo en el edificio.

${ }^{35}$ La existencia de múltiples cuadernos repletos de anotaciones en el Archivo Félix Hernández, dan fe de la abrumadora cantidad de medidas que se tomaron para la elaboración de este levantamiento.
}

Arch. esp. arte, LXXXVIII, 349, ENERO-MARZO 2015, 1-18

ISSN: 0004-0428, eISSN: 1988-8511, doi: 10.3989/aearte.2015.01 


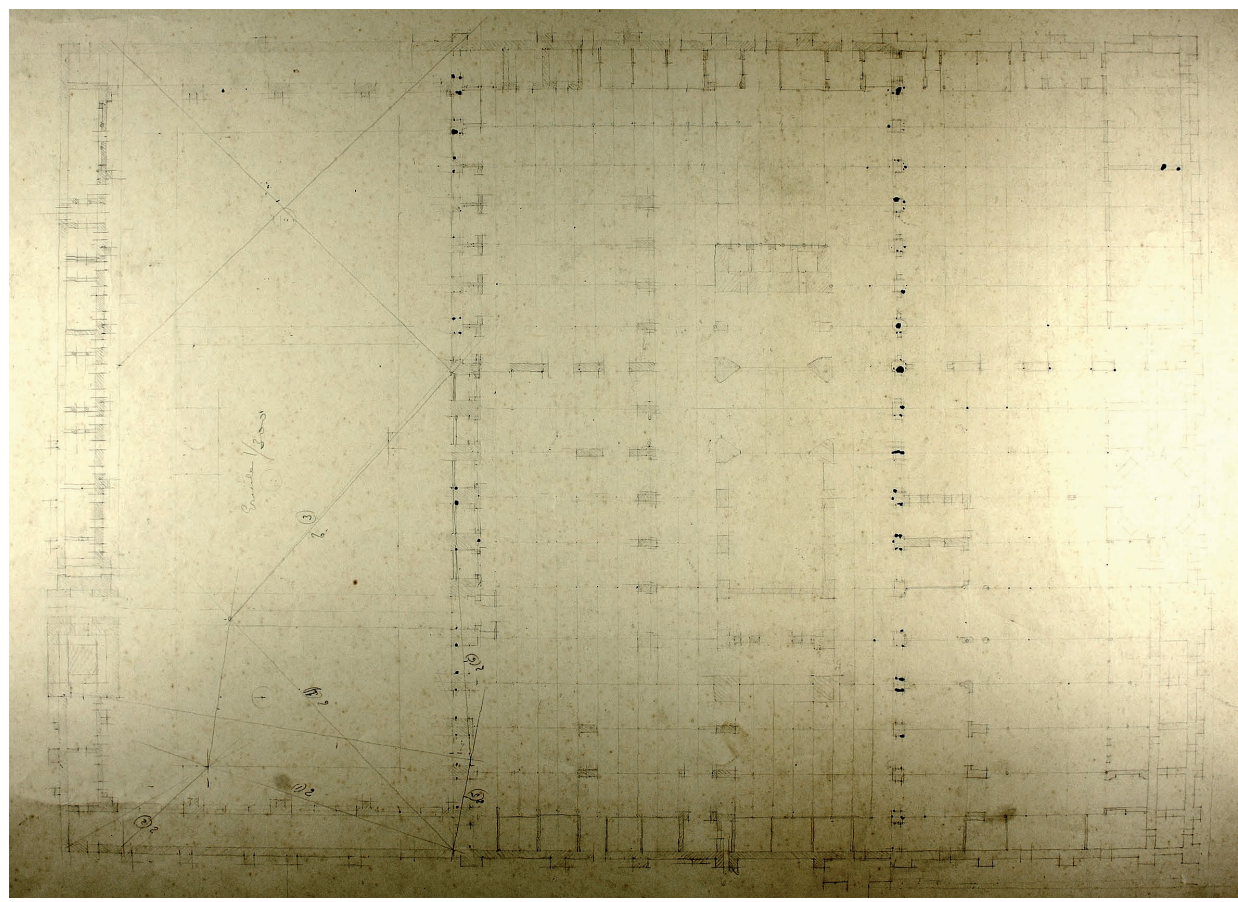

Fig. 11. Félix Hernández. Planta preparatoria para el levantamiento planimétrico, escala 1:300, s/f. Museo Arqueológico de Córdoba, Archivo Félix Hernández, carpeta 8.

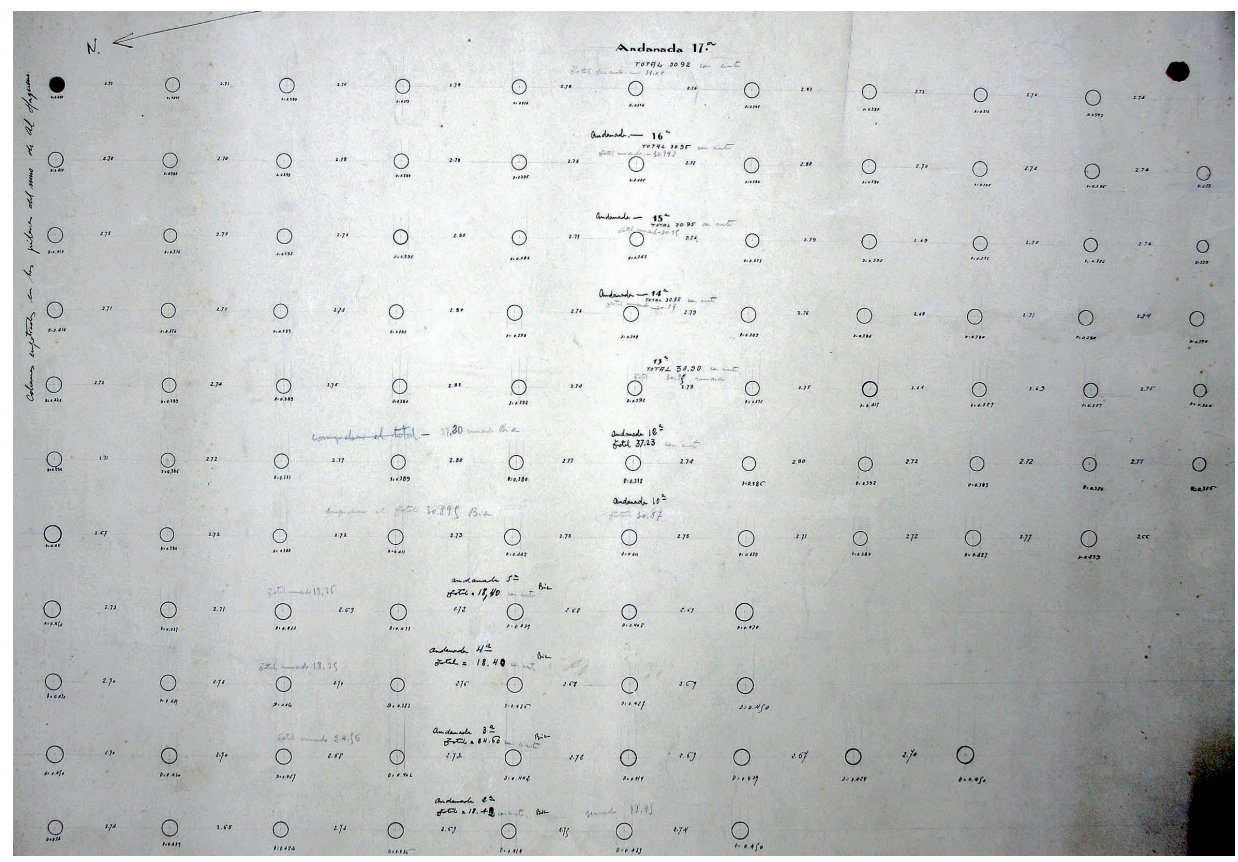

Fig. 12. Félix Hernández. Toma de datos esquemática preparatoria para el levantamiento planimétrico, s/e, s/f. Museo Arqueológico de Córdoba, Archivo Félix Hernández, plano nº 53.

Arch. esp. arte, LXXXVIII, 349, ENERO-MARZO 2015, 1-18 ISSN: 0004-0428, eISSN: 1988-8511, doi: 10.3989/aearte.2015.01 
plantilla, organizada en base a andanadas de arcos, necesaria para alojar la toma de datos para la segunda hoja del levantamiento. A la condición de medio que posee el dibujo para aprehender la realidad, se le une el carácter expresivo que pueda tener en sí mismo. En este caso, es capaz de transmitir desde la abstracción esa condición del espacio que cualifican las columnas, evocando desde el dibujo el sentido isótropo del fragmento de la Mezquita que representa.

\section{Graduación en las intervenciones}

El análisis de los primeros trabajos realizados resulta esclarecedor del estado del edificio que recibe y sobretodo de lo que Hernández entiende por prioritario. En los proyectos de la década de los 40 aparece reflejada no sólo la búsqueda de lo original, sino también una serie de medidas tendentes al más puro mantenimiento. La gran extensión de las cubiertas de la Mezquita-Catedral y la fragilidad del sistema constructivo de evacuación de aguas pluviales hacían necesaria una labor continuada que garantizara el correcto funcionamiento de la red de canales. La importancia de las labores propias de conservación había sido otra de las cuestiones consagradas en la Carta de Atenas y de hecho Antonio Flórez en su etapa de conservador del edificio entre 1924 y 1929 había avanzado notablemente en su consideración. Por tal motivo, la mayoría de las intervenciones en el edificio tras la Guerra hicieron especial hincapié en preservar la vida del edificio con una adecuada funcionalidad, insistiendo en el arreglo de tejados, muretes y revestimientos de plomo de las canales. Confluían en este punto necesidad y conveniencia, en contraposición a otras ambiciones.

A pesar de su frustrado primer proyecto, la mayoría de las intervenciones que proyectó Hernández fueron rigurosamente seleccionadas y modestas tanto en su extensión como en sus pretensiones. De esta forma, podemos confrontar su trabajo con otro tipo de entendimiento vigente en la posguerra, por el que se consideraba que la tarea del restaurador debía ser una última y definitiva etapa en la historia del monumento. Hernández no persiguió una unidad rotunda, situándose en una posición más cercana al modo de trabajo de Ferrant o de Íñiguez Almerch. En esta forma de enfrentarse a la restauración se conjugaban factores como la limitada capacidad económica, la complejidad de los edificios en cuestión o el escaso conocimiento previo, lo que justificaba la imposibilidad de un acercamiento clarividente. Hernández tampoco contempló nunca una restauración integral. Era consciente que los interrogantes que aún guardaba la Mezquita hacían inviable la llegada a ese estado definitivo. Pero el hecho de que no considerara la posibilidad de llegar a tal estado no significaba que no fuera formando poco a poco una imagen de lo que debía ser el edificio, reconociéndose la búsqueda de lo original, como idea recurrente.

Nos parece importante insistir que Hernández confirma también la graduación en las intervenciones como criterio. Si rastreamos en los trabajos de Ferrant o de Íñiguez podemos encontrar también ejemplos en los que existe una programada diferente intensidad en las intervenciones de cada edificio. No siempre es necesario llegar a una reconstrucción y tal vez no es suficiente con la estricta conservación. Cada elemento, cada zona, en su complejidad, puede necesitar un diferente grado de intervención. Esta cuestión fue asumida por Hernández y supeditada en su caso a la mejora de la comprensión del edificio, avanzándose por tanto una interpretación muy cercana a la de nuestros días.

A partir de 1972 y hasta su fallecimiento en 1975, Félix Hernández vio cómo la Dirección General de Arquitectura empezó a intervenir en el edificio, proponiendo y realizando actuaciones tremendamente simplificadoras de la complejidad del edificio, contraviniendo de paso el común entendimiento científico tras la Carta de Venecia.

Arch. esp. arte, LXXXVIII, 349, ENERO-MARZO 2015, 1-18

ISSN: 0004-0428, eISSN: 1988-8511, doi: 10.3989/aearte.2015.01 


\section{BIBLIOGRAFÍA}

Bermúdez Cano, José Manuel (2010): "El atrium del complejo episcopal cordubensis: Una propuesta sobre la funcionalidad de las estructuras tardoantiguas del Patio de la Mezquita de Córdoba". En Romula, $\mathrm{n}^{\circ}$ 9, pp. 315-341.

Casar Pinazo, José Ignacio y Esteban Chapapría, Julián (eds.) (2008): Bajo el signo de la victoria. La conservación del patrimonio durante el primer franquismo (1936-1958), Valencia, Pentagraf.

Esteban Chapapría, Julián (2007): La conservación del patrimonio español durante la II República (19311939), Barcelona, Fundación Caja de Arquitectos.

Fernández-Puertas, Antonio (1975): "Bosquejo sobre la labor científica de don Félix Hernández Giménez". En Cuadernos de la Alhambra, n 10-11, pp. 1-10.

Fernández-Puertas, Antonio (2009): Mezquita de Córdoba. Su estudio arqueológico en el siglo XX, Granada, Universidad de Granada.

Gómez de Terreros Guardiola, María del Valle (1999): "El pavimento del Patio de los Naranjos de la Catedral de Sevilla. Los proyectos de Félix Hernández Giménez”. En Laboratorio de Arte: Revista del Departamento de Historia del Arte, ${ }^{\circ}$ 12, pp. 371-384.

Gómez de Terreros Guardiola, María del Valle y Díaz Zamorano, María Ascensión (2002): "La restauración del patio de los Naranjos de la catedral de Sevilla. Los proyectos de Félix Hernández Giménez". En Magna Hispalense (I). Recuperación de la aljama almohade, Sevilla, Aula Hernán Ruiz y Cabildo Metropolitano, pp. 33-113.

González-Varas Ibáñez, Ignacio (1999): Conservación de bienes culturales. Teoría, historia, principios y normas, Madrid, Cátedra.

Hernández Giménez, Félix (1928): “Arte musulmán. La techumbre de la Gran Mezquita de Córdoba”. En Archivo Español de Arte y Arqueología, IV, pp.191-225.

Hernández Giménez, Félix (1961): El codo en la historiografía árabe de la Mezquita Mayor de Córdoba. Contribución al estudio del monumento, Madrid, Maestre.

Hernández Giménez, Félix (1975): El alminar de Abd Al-Rahman III en la Mezquita Mayor de Córdoba. Génesis y repercusiones, Granada, Patronato de la Alhambra.

Marfil Ruiz, Pedro (2000): "La sede episcopal cordobesa en época bizantina: evidencia arqueológica". En V Reunión de Arquelogía Cristiana Hispánica, Cartagena, pp. 157-176.

Mogollón Cano-Cortés, María Pilar (2011): La restauración monumental durante la posguerra en Extremadura y la Dirección General de Bellas Artes 1940-1958, Cáceres, Universidad de Extremadura, Servicio de Publicaciones.

Muñoz Cosme, Alfonso (1989): La conservación del patrimonio arquitectónico español, Madrid, Ministerio de Cultura, Dirección General de Bellas Artes y Archivos.

Nieto Cumplido, Manuel (1998): La Catedral de Córdoba, Córdoba, Obra Social y Cultural de CajaSur.

Nieto Cumplido, Manuel y Luca de Tena alvear, Carlos (1992): La Mezquita de Córdoba: planos y dibujo, Córdoba, Colegio Oficial de Arquitectos de Andalucía Occidental.

Ruiz Cabrero, Gabriel (2009): Dibujos de la Catedral de Córdoba. Visiones de la Mezquita, Madrid, Cabildo Catedral de Córdoba, This Side Up.

Vicent Zaragoza, Ana María (1976): "Perfil biográfico y humano de don Félix Hernández Giménez". En Corduva, vol. I, n 3, pp. 163-198.

Fecha de recepción: 21-I-2014

Fecha de aceptación: 8-X-2014

Arch. esp. arte, LXXXVIII, 349, ENERO-MARZO 2015, 1-18 ISSN: 0004-0428, eISSN: 1988-8511, doi: 10.3989/aearte.2015.01 